\title{
Psychological capital dan kepuasan kerja sebagai anteseden organizational citizenship behavior pada tenaga pendidik
}

\author{
Albert Kurniawan Purnomo* \\ Program Studi Manajemen, Fakultas Ekonomi, Universitas Nurtanio Bandung \\ Jl. Pajajaran 219. Bandung. 40174. Indonesia \\ kurniawanalbert@unnur.ac.id \\ *Penulis Korespondensi
}

Submitted: Dec 10, 2018; Reviewed: Dec 24, 2018; Accepted: Jan 30, 2019

\begin{abstract}
The purpose of this study is to identify the factors that encourage Organizational Citizenship Behavior (OCB) educators. Two independent variables can be identified are Pschological Capital and Satisfaction. Pschological Capital contributes the most influence to Organizational Citizenship Behavior (OCB). If the educators have been satistied, OCB will be created in the college environment. Data analysis is using SEM technique with WarpPLS 6.0 software. The target of this research was expected to educators able to run collaboration and cooperation in teaching, research, and community service, ultimately able to improve college performance. The result of this research Pschological Capital and Satisfaction direct effect to Organizational Citizenship Behavior (OCB), but no indirect effect Pschological Capital to Organizational Citizenship Behavior (OCB).
\end{abstract}

Keywords: educators; organizational citizenship behavior; psychological capital; satisfaction

\begin{abstract}
Abstrak: Tujuan dari penelitian ini adalah untuk mengidentifikasi faktor-faktor yang mendorong Organizational Citizenship Behavior (OCB) tenaga pendidik. Dua variabel independen yang dapat diidentifikasi adalah Modal Psikologis dan Kepuasan. Modal Psikologis berkontribusi paling besar terhadap Organizational Citizenship Behavior (OCB). Jika pendidik telah puas, OCB akan tercipta di lingkungan perguruan tinggi. Analisis data menggunakan teknik SEM dengan software aplikasi WarpPLS 6.0. Target penelitian ini diharapkan para pendidik dapat berkolaborasi dan bekerja sama menjalankan pengajaran, penelitian, dan pengabdian kepada masyarakat, yang pada akhirnya mampu meningkatkan kinerja perguruan tinggi. Hasil penelitian ini Modal Psikologis dan Kepuasan berpengaruh langsung terhadap Organizational Citizenship Behavior (OCB), tetapi tidak ada pengaruh tidak langsung Modal Psikologis terhadap Organizational Citizenship Behavior (OCB).
\end{abstract}

Kata kunci: kepuasan; organizational citizenship behavior; psychological capital; tenaga pendidik

\section{PENDAHULUAN}

Perilaku tenaga pendidik (dosen) akan menentukan kesuksesan perguruan tinggi, dengan visi misi yang terarah akan membawa perguruan tinggi menduduki ranking posisi skala nasional maupun internasional. Perilaku yang baik ditunjang oleh partisipasi tenaga pengajar di dalamnya, dan dalam kaitannya dengan peningkatan kualitas partisipasi, dikenal istilah Organizational Citizenship Behavior (OCB). Konsep OCB mengacu pada teori Organ, 1988; Kurniawan, 2015. Fakta menunjukkan bahwa 
organisasi dan Organizational Citizenship Behavior yang baik akan tercerminkan dari tindakan yang melebihi apa yang menjadi standar institusi (Darmawanti \& Herlina, 2013; Kurniawan, 2015).

Studi literatur Bambale (2014) mengidentifikasi kinerja menjadi tiga kategori yaitu: kinerja berorientasi pada tugas, kinerja pada tanggung jawab tambahan (ekstra), dan kontraproduktif dalam pekerjaan. Kinerja berorientasi pada tugas berfokus pada efektivitas karyawan dalam melakukan tugas tanggung jawab utamanya dan memberikan manfaat dasar bagi institusi, secara singkatnya kinerja berorientasi tugas, peran anggota institusi hanya sebatas memenuhi job description secara formal. Kinerja pada tanggung jawab tambahan (ekstra) atau dikenal dengan istilah OCB (Organizational Citizenship Behavior) merupakan aktivitas sukarela dari anggota institusi dengan maksud mendukung institusi, sikap perilaku lebih bersifat menolong dinyatakan dengan sikap tidak mementingkan diri sendiri dan lebih berfokus pada kesejahteraan anggota lain (Rahmayanti dkk., 2014; Kurniawan, 2015). Counterproductive Work Behavior (CWB) adalah perilaku anggota organisasi yang bersifat merusak atau merugikan kepentingan organisasi (Bambale, 2014). OCB dan CWB bersifat kontradiktif berlawanan, OCB lebih membawa perbaikan bagi institusi, sedangkan CWB membahayakan institusi.

Kurniawan (2015) mengungkapkan dimensi OCB adalah altruism, conscientiousness, sportmanship, civic virtue, dan courtesy. Dalam riset ini, berfokus pada konsep positif OCB. Luthans \& Mhatre (2011) menyatakan bahwa terdapat hubungan positif signifikan psycap dengan perilaku dalam organisasi yang di dalamnya meliputi OCB, kepuasan kerja, komitmen, dan kesejahteraan psikologis. Menurut riset lain menyebutkan psycap memiliki pengaruh terhadap OCB (Julianti \& Dewayani, 2015). Penelitian Julianti \& Dewayani ini menyebutkan bahwa sub variabel hope secara signifikan memengaruhi OCB. Individu yang memiliki harapan tinggi akan lebih tekun dan mengusahakan diri untuk meraih kesuksesan dalam pekerjaan (membantu rekan kerja, mempunyai empati dan perhatian personal pada orang lain). Luthans (2011) menyebutkan bahwa hope melibatkan willpower yang akan memicu motivasi dan menjaga energi seseorang untuk meraih tujuan.

Faktor lain yang memberikan kontribusi peningkatan OCB adalah kepuasan anggota institusi. Susanto (2015) menyatakan akibat dari makin tingginya kepuasan anggota institusi, maka timbul persahabatan erat dan terjadi hubungan harmonis antar anggota dan lingkungan kerja, dampak akhirnya mampu menciptakan Organizational Citizenship Behavior (OCB). Penelitian lain menunjukkan hasil kepuasan kerja memiliki hubungan dan pengaruh positif dengan OCB (Triyanto \& Santosa, 2009).

Dari latar belakang, maka peneliti merumuskan beberapa masalah sebagai berikut:

1. Apakah terdapat pengaruh psycap terhadap Organizational Citizenship Behavior tenaga pendidik?

2. Apakah terdapat pengaruh kepuasan kerja terhadap Organizational Citizenship Behavior tenaga pendidik?

3. Apakah terdapat pengaruh psycap terhadap kepuasan kerja tenaga pendidik?

4. Apakah terdapat pengaruh tidak langsung psycap terhadap Organizational Citizenship Behavior yang dimediasi kepuasan kerja tenaga pendidik?

Penelitian ini bertujuan untuk menjawab rumusan masalah yang telah dipaparkan, yaitu untuk mengetahui:

1. Pengaruh psycap terhadap Organizational Citizenship Behavior tenaga pendidik.

2. Pengaruh kepuasan kerja terhadap Organizational Citizenship Behavior tenaga pendidik.

3. Pengaruh psycap terhadap kepuasan kerja tenaga pendidik.

4. Pengaruh tidak langsung psycap terhadap Organizational Citizenship Behavior yang dimediasi kepuasan kerja tenaga pendidik.

\section{METODE}

Metode penelitian yang digunakan adalah metode kuantitatif. Metode kuantitatif yaitu metode statistik, yang mana cara pengumpulan, cara pencarian masalah, cara pengolahan data hingga pengambilan kesimpulannya dilakukan secara objektif, yang mana peneliti tidak harus langsung terlibat (involved) dan menggunakan sampel sebagai sumber data. Pengumpulan data menggunakan kuesioner serta diolah dengan menggunakan WarpPLS 6.0 dan teknik analisis mediasi (intervening). 
Populasi dan Sampel

Populasi dari penelitian ini adalah tenaga dosen Perguruan Tinggi Swasta menurut pendidikan di Kopertis Wilayah IV Jawa Barat, 2016 (diunduh dari BPS Maret 2018) berjumlah 20.660 dosen. Dalam penelitian ini, teknik pengambilan sampel menggunakan teknik non probability sampling dengan pendekatan purposive random sampling, yang mana yang dijadikan sampel adalah dosen tetap dan telah memiliki jabatan fungsional (JABFUNG). Sampel yang digunakan adalah tenaga pendidik (dosen) yang berada di lingkup perguruan tinggi Wilayah Kopertis IV, sebanyak 54 responden saja berhasil didapatkan, karena sampel kecil kurang dari 100, maka menggunakan PLS.

Definisi Operasional Variabel

Variabel yang diteliti meliputi psycap, kepuasan kerja, dan Organizational Citizenship Behavior. Ketiga variabel ini dapat diukur dengan beberapa indikator pernyataan sebagai berikut:

Organizational Citizenship Behavior dapat dijabarkan ke dalam 5 dimensi yaitu (1) Altruism, dengan indikator: Saya bersedia membantu rekan kerja yang beban kerjanya berlebihan; (2) Courtesy dengan indikator: Saya menghargai sesama rekan kerja apa pun jabatannya; (3) Sportsmanship, dengan indikator: Saya menerima kebijakan yang berlaku di tempat saya kerja; (4) Conscientiousness, dengan indikator: Saya mau melakukan pekerjaan lebih walaupun tidak ada yang meminta; dan (5) Civic Virtue, dengan indikator: Saya selalu berpartisipasi dalam berbagai kegiatan yang diselenggarakan oleh organisasi (Gunawan, I Kadek \& Netra, 2017).

Kepuasan kerja dijelaskan oleh 5 dimensi: (1) Pekerjaan, dengan indikator: Perusahaan telah menempatkan karyawan sesuai dengan keterampilannya; (2) Rekan kerja, dengan indikator: Rekan kerja saya di kantor menyenangkan; (3) Pembayaran, dengan indikator: Gaji yang diberikan sesuai dengan kompetensi/keahlian; (4) Promosi, dengan indikator: Perusahaan yang menyediakan pengembangan jalur karir yang jelas kepada pegawainya; dan (5) Pengawasan, dengan indikator: Cara atasan (manajer) saya melakukan pengawasan (Susanto, 2015).

Indikator psycap dijabarkan 24 item sesuai dengan teori Psycological Capital Questionnaire (PCQ) (Luthans, et al., 2007; Gorgens-Ekermans \& Herbert, 2013), dengan empat dimensi: (1) Hope, dengan 6 indikator; (2) Self-Efficacy, dengan 6 indikator; (3) Resiliency, dengan 6 indikator; dan (4) Optimism, dengan 6 indikator.

\section{HASIL DAN PEMBAHASAN}

Teknik analisis data dalam penelitian ini menggunakan analisis jalur, dimana terdapat variabel eksogen (Psycap), variabel endogen (Organizational Citizenship Behavior) dan satu variabel intervening/mediasi yaitu Kepuasan Kerja.

Hasil Analisis Pengujian Model

Tabel 1. Measurement models

\begin{tabular}{lll}
\hline Fit Indicates & $\begin{array}{l}\text { Recommended } \\
\text { Value }\end{array}$ & Value \\
\hline AVIF & $<=3,3$ & 1,000 \\
AFVIF & $<=3,3$ & 1,137 \\
GoF & $>=0,25$ (medium) & 0,276 \\
RSCR & $>=0,9$ & 1,000 \\
SSR & $>=0,7$ & 1,000 \\
\hline
\end{tabular}

Sumber: Hasil pengolahan WarpPLS (2018)

Analisis model pengukuran menggunakan beberapa ukuran yang disesuaikan dengan syarat software WarpPLS, ada lima (5) ukuran dasar, dan semuanya memenuhi syarat. 
Tabel 2. Validitas loading factor

\begin{tabular}{cccc}
\hline & OCB & K & PC \\
\hline OCB1 & 0,702 & & \\
OCB2 & 0,670 & & \\
OCB3 & 0,706 & & \\
OCB4 & 0,750 & & \\
K1 & & 0,853 & \\
K2 & & 0,616 & \\
K3 & & 0,751 & \\
K4 & & 0,904 & \\
K5 & & 0,819 & \\
PC1 & & & 0,716 \\
PC2 & & & 0,744 \\
PC3 & & & 0,670 \\
PC4 & & & 0,706 \\
PC5 & & & 0,711 \\
PC6 & & & 0,675 \\
PC7 & & & 0,607 \\
PC8 & & & 0,739 \\
PC9 & & & 0,712 \\
PC10 & & & 0,712 \\
PC12 & & & 0,655 \\
PC13 & & & 0,612 \\
PC14 & & & 0,549 \\
PC15 & & & 0,674 \\
PC18 & & & 0,512 \\
PC21 & & & 0,503 \\
PC22 & & & 0,744 \\
\hline Sum & &
\end{tabular}

Sumber: Hasil pengolahan WarpPLS (2018)

Tahap berikutnya adalah pengujian analisis faktor, yang mana syarat minimal yang dikehendaki harus memiliki nilai di atas 0,50 (Hair et al., 2006) dan semua indikator pernyataan memiliki nilai di atas ketentuan, kecuali beberapa item pernyataan psycap ada yang tidak terpenuhi dan tidak dimunculkan dalam hasil.

Tabel 3. Hasil uji reliabilitas

\begin{tabular}{ccc}
\hline Variabel & $\begin{array}{c}\text { Composite } \\
\text { Reliability }\end{array}$ & $\begin{array}{c}\text { Cronbach } \\
\text { Alpha }\end{array}$ \\
\hline OCB & 0,800 & 0,667 \\
K & 0,894 & 0,849 \\
PC & 0,935 & 0,925 \\
\hline
\end{tabular}

Sumber: Hasil pengolahan WarpPLS (2018)

Dari pengujian reliabilitas, memiliki syarat composite reliability minimal 0,70; dan Cronbach Alpha minimal 0,60 (Jogiyanto \& Abdillah, 2009), dari hasil pengujian reliabilitas, semua variabel laten memenuhi syarat minimal 0,60 .

Hasil Pengujian Deskriptif

Dalam point ini akan dijabarkan pengujian secara deskriptif dari 3 (tiga) variabel yaitu Organizational Citizenship Behavior (OCB), kepuasan, dan psycap.

Berikut hasil uji deskriptif dari ketiga variabel: 
Tabel 4. Hasil uji deskriptif

\begin{tabular}{llll}
\hline Variabel & Indikator & $\begin{array}{l}\text { Rata- } \\
\text { Rata }\end{array}$ & Kesimpulan \\
\hline Organizational & OCB1 & 3,93 & Tinggi \\
Citizenship & OCB2 & 4,56 & Sangat Tinggi \\
Behavior & OCB3 & 3,91 & Tinggi \\
(OCB) & OCB4 & 3,61 & Tinggi \\
& OCB & 4,00 & Tinggi \\
& K1 & 3,44 & Tinggi \\
& K2 & 4,07 & Tinggi \\
Kepuasan & K3 & 3,04 & Cukup Tinggi \\
& K4 & 3,30 & Cukup Tinggi \\
& K5 & 3,39 & Cukup Tinggi \\
& K & 3,45 & Tinggi \\
& PC1 & 3,15 & Cukup Tinggi \\
& PC2 & 3,00 & Cukup Tinggi \\
& PC3 & 3,41 & Tinggi \\
& PC4 & 3,26 & Cukup Tinggi \\
& PC5 & 3,52 & Tinggi \\
& PC6 & 3,48 & Tinggi \\
& PC7 & 3,22 & Cukup Tinggi \\
Pscychological & PC8 & 3,35 & Cukup Tinggi \\
& PC9 & 3,33 & Cukup Tinggi \\
& PC10 & 3,61 & Tinggi \\
& PC12 & 3,59 & Tinggi \\
& PC13 & 3,26 & Cukup Tinggi \\
& PC14 & 3,33 & Cukup Tinggi \\
& PC15 & 3,41 & Tinggi \\
& PC18 & 3,31 & Cukup Tinggi \\
& PC21 & 3,98 & Tinggi \\
& PC22 & 3,00 & Cukup Tinggi \\
& PC & 3,08 & Cukup Tinggi \\
\hline Sulal & &
\end{tabular}

Sumber: Hasil pengolahan Ms. Excell (2018)

Klasifikasi rata-rata dan kesimpulan didasarkan pada Umar (2019) \& Purnomo (2019), yang membagi kriteria menjadi 5 (lima):

Tabel 5. Klasifikasi kelas interval

\begin{tabular}{lc}
\hline Kriteria & Interval \\
\hline Ssangat Tidak Tinggi & $1,00-1,80$ \\
Tidak Tinggi & $>1,80-2,60$ \\
Cukup Tinggi & $>2,60-3,40$ \\
Tinggi & $>3,40-4,20$ \\
Sangat Tinggi & $>4,20-5,00$ \\
\cline { 1 - 1 } Sumber: Umar (2019) \& Purnomo (2019) \\
Hasil Pengujian Inner Model \\
Pengujian model dengan WarpPLS dimulai dengan menganalisis $R$-square untuk setiap variabel laten \\
dependen. Perubahan nilai $R$-square berguna untuk menilai variabel laten eksogen tertentu terhadap \\
variabel endogen yang mempunyai pengaruh substantif. Tabel 6 memperlihatkan output estimasi $R$ - \\
Square.
\end{tabular}


Tabel 6. Nilai $R$-Square

\begin{tabular}{ll}
\hline Variabel Dependen & $R$-Square \\
\hline Kepuasan Kerja & 0,05 \\
Organizational Citizenship Behavior & 0,24 \\
\hline
\end{tabular}

Sumber: Hasil pengolahan WarpPLS (2018)

Selain menggunakan $R$-Square, goodness of fit, model juga diukur dengan menggunakan $Q$-Square predicate relevance untuk model struktural, mengukur seberapa baik observasi yang dihasilkan oleh model dan juga estimasi parameternya. Nilai $Q$-Square $>0$ menunjukkan model memiliki predicate relevance, sebaliknya jika nilai $Q$-Square $\leq 0$ menunjukkan model tidak memiliki predicate relevance. Nilai predicate relevance $\left(\mathrm{Q}^{2}\right)$, yaitu:

$\mathrm{Q}^{2}=1-\left(1-\mathrm{R}_{1}{ }^{2}\right)\left(1-\mathrm{R}_{2}{ }^{2}\right)$

$\mathrm{Q}^{2}=1-(1-0,05)(1-0,24)$

$\mathrm{Q}^{2}=1-(0,95)(0,76)$

$\mathrm{Q}^{2}=1-(0,7220)$

$\mathrm{Q}^{2}=0,2780$

Perhitungan tersebut menunjukkan nilai $\mathrm{Q}^{2}$ lebih besar dari $0(0,2780)$, maka dapat diinterprestasikan bahwa model baik dan layak digunakan karena memiliki nilai prediktif yang relevan, yaitu sebesar 27,80\% variabel Organizational Citizenship Behavior (OCB) mampu dijelaskan oleh variabel-variabel yang digunakan.

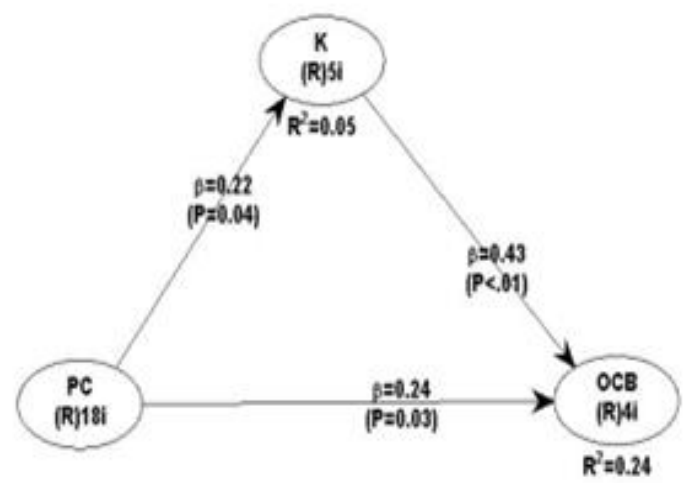

Gambar 1: Analisis jalur psycap, kepuasan, dan organizational citizenship behavior Sumber: Hasil pengolahan WarpPLS (2018)

Pengujian Inferesial (Uji Hipotesis)

Parameter pengukuran tentang ada tidaknya pengaruh dan signifikan secara parsial antara variabel eksogen dan endogen dapat diketahui berdasarkan nilai-nilai dengan ketentuan sebagai berikut:

Tabel 7. Hasil pengujian model persamaan struktural

\begin{tabular}{clccc}
\hline Hipotesis & Pengaruh & Koefisien & Probabilitas & Kesimpulan \\
\hline H1 & PsyCap $\rightarrow$ OCB & 0,24 & 0,04 & Diterima \\
H2 & Kepuasan Kerja $\rightarrow$ OCB & 0,43 & $<0,001$ & Diterima \\
H3 & PsyCap $\rightarrow$ Kepuasan Kerja & 0,22 & 0,03 & Diterima \\
H4 & PsyCap $\rightarrow$ Kepuasan Kerja $\rightarrow$ OCB & 0,095 & 0,156 & Tidak dapat diterima \\
\hline
\end{tabular}

Sumber: Hasil pengolahan WarpPLS (2018)

Pembahasan

Tabel 7 menjelaskan tentang nilai-nilai yang dapat digunakan untuk menguji hipotesis dalam penelitian yaitu sebagai berikut: 
1. Nilai koefisien standardized regression pengaruh psycap $\left(\mathrm{X}_{1}\right)$ terhadap Organizational Citizenship Behavior (Y) sebesar 0,24, artinya jika psycap naik maka Organizational Citizenship Behavior juga naik sebesar 0,24. Nilai probabilitas sebesar 0,04, maka dapat disimpulkan bahwa pengaruh psycap $\left(\mathrm{X}_{1}\right)$ terhadap Organizational Citizenship Behavior $(\mathrm{Y})$ adalah signifikan. Jadi, hipotesis pertama yang menyatakan psycap berpengaruh secara signifikan terhadap Organizational Citizenship Behavior dapat diterima.

Hasil ini sejalan dengan Jung \& Yoon, (2015); suasana positif tempat kerja karyawan atau perasaan positif karyawan juga meningkatkan OCB mereka. Penelitian ini juga menganalisis hubungan antara masing-masing komponen psycap (self-efficacy, harapan, ketahanan, dan optimism) terhadap OCB. Ini bisa dilakukan karena psycap adalah konstruksi multidimensi yang bisa dipatahkan oleh masing-masing komponennya. Dengan meningkatnya psycap dan komponennya, OCB juga meningkat (Golestaneh, 2014).

2. Nilai koefisien standardized regression pengaruh kepuasan kerja $(Z)$ terhadap Organizational Citizenship Behavior (Y) sebesar 0,43, artinya jika kepuasan kerja naik maka Organizational Citizenship Behavior juga meningkat sebesar 0,43. Nilai probabilitas sebesar <0,001, maka dapat disimpulkan bahwa pengaruh kepuasan kerja (Z) terhadap Organizational Citizenship Behavior (Y) adalah signifikan. Jadi, hipotesis kedua yang menyatakan kepuasan kerja berpengaruh secara signifikan terhadap Organizational Citizenship Behavior dapat diterima.

Penelitian sebelumnya telah dilakukan oleh beberapa peneliti di antaranya Mehboob, 2012; Unal, 2013; Ibrahim et al., 2013; dan Basirudin et al., 2016 yang menyatakan bahwa kepuasan kerja memiliki pengaruh signifikan terhadap Organizational Citizenship Behavior, sedangkan beberapa peneliti lainnya menyatakan sebaliknya, tidak terdapat pengaruh signifikan kepuasan kerja terhadap Organizational Citizenship Behavior yang dinyatakan oleh Sedarmayanti \& Kuswanto (2015); Gunawan \& Masruroh (2013), dan Unal (2013).

3. Nilai koefisien standardized regression pengaruh psycap $\left(\mathrm{X}_{1}\right)$ terhadap Kepuasan Kerja $(\mathrm{Z})$ sebesar 0,22 , artinya jika psycap naik maka kepuasan kerja juga naik sebesar 0,22 . Nilai probabilitas sebesar 0,03, maka dapat disimpulkan bahwa pengaruh psycap $\left(\mathrm{X}_{1}\right)$ terhadap Kepuasan Kerja $(\mathrm{Z})$ adalah signifikan. Jadi, hipotesis ketiga yang menyatakan psycap berpengaruh secara signifikan terhadap kepuasan kerja dapat diterima.

Hasil ini sejalan dengan penelitian psycap berkontribusi terhadap kepuasan kerja dapat sangat relevan untuk mengembangkan pemahaman yang lebih baik tentang peran positif dalam lingkungan bisnis Afrika Utara (Badran \& Youssef-Morgan; 2015).

4. Nilai besar mediasi (pengaruh tidak langsung) adalah 0,095. Didapatkan dari hasil perkalian standardized regression psycap $\rightarrow$ kepuasan kerja $(0,22)$ dan kepuasan kerja $\rightarrow$ Organizational Citizenship Behavior $(0,43)$; dan secara uji probabilitas 0,156, artinya bahwa kepuasan kerja tidak mampu memediasi pengaruh psycap terhadap Organizational Citizenship Behavior.

Hal ini adalah temuan baru pengembangan model yang dilakukan oleh peneliti. Sejauh ini peneliti belum menemukan penelitian yang sama.

\section{SIMPULAN DAN SARAN}

Hasil penelitian ini dapat disimpulkan bahwa variabel psychological capital berpengaruh terhadap Organizational Citizenship Behavior, yang mana variabel kepuasan kerja belum mampu menjadi mediasi. Penelitian ini menghasilkan beberapa temuan krusial, di antaranya sebagai berikut: psycap yang merupakan model modal psikologi untuk melayani mahasiswa maupun rekan sejawat di lingkungan tenaga pendidik dan akhirnya diharapkan mampu meningkatkan Organizational Citizenship Behavior. Apabila anggota organisasi memiliki kepuasan dalam memandang pekerjaan, maka secara langsung akan meningkatkan Organizational Citizenship Behavior. Tenaga pendidik yang siap akan memiliki rasa percaya diri, dan tahan terhadap tekanan, maka tanpa disadari kepuasan dalam bekerja akan meningkat secara signifikan karena apa yang akan dijalankan sesuai dengan pemikiran dan tanpa paksaan. Kesimpulan terakhir sekaligus temuan baru dan keterbatasan berkaitan dengan peran kepuasan kerja yang belum mampu menjadi mediasi/intervening pengaruh psycap terhadap Organizational Citizenship Behavior. 
Berdasarkan hasil temuan, maka beberapa hal dapat disarankan kepada pihak perguruan tinggi mengenai peningkatan Organizational Citizenship Behavior anggota. Dari hasil penelitian, terlihat bahwa psycap berpengaruh terhadap Organizational Citizenship Behavior; yang perlu ditingkatkan adalah peran anggota organisasi (tenaga pendidik) untuk mengembangkan dan membudidayakan psycap di lingkungan kerja, khususnya menyiapkan organisasi untuk membuat kontribusi positif terhadap lingkungannya melalui program pengabdian masyarakat. Berkaitan dengan kepuasan kerja yang berpengaruh juga pada Organizational Citizenship Behavior, yang perlu ditingkatkan adalah suasana/iklim organisasi, dengan menciptakan kondisi lebih nyaman dan menyenangkan untuk bekerja agar anggota organisasi dapat memaksimalkan talenta. Dari hasil penelitian, terlihat bahwa psycap berpengaruh terhadap kepuasan kerja; dapat disarankan agar pihak pimpinan mempertimbangkan peningkatkan gaji yang diberikan agar disesuaikan dengan kompetensi/keahlian dan beban kerja sebagai wujud apresiasi, yang pada akhirnya akan terjadi bahwa kepuasan kerja meningkat.

Peneliti juga menyarankan agar pimpinan dengan bijak, agar mendorong anggotanya berpartisipasi dalam berbagai kegiatan yang diselenggarakan oleh organisasi; serta menciptakan perilaku positif yang mengarah ke bentuk empati, yang mana pimpinan mengingatkan anggotanya untuk saling membantu di antara rekan kerja yang beban kerjanya berlebihan. Sebagai tambahan, saran untuk peneliti berikutnya untuk menambahkan sampel penelitian agar tujuan penelitian keempat bisa terpenuhi dan menambahkan variabel lain seperti Leadership Membership Exchange (LMX) atau Transformasional Leadership.

\section{ACKNOWLEDGEMENT}

Ucapan terima kasih disampaikan kepada pihak Universitas Nurtanio Bandung yang telah memberikan dukungan moril dan semangat kepada peneliti, serta kepada para responden yang telah berkenan berpartisipasi dalam hal pengisian kuesioner.

\section{REFERENSI}

Avolio \& Luthans. (2007). The mediating role of psychological capital in the supportive organizational climate-employee performance relationship. Journal of Organizational Behavior, in Press

Badran, A.M., \& Youssef-Morgan, M. (2015). Psychological capital and job satisfaction in egypt. Journal of Managerial Psychology, Vol. 30 Issue: 3, pp.354-370

Bambale, A.J. (2014). Relationship between servant leadership and organizational citizenship behaviors: review of literature and future research directions. Journal of Marketing and Management, 5(1),1-16

Basirudin, Basiruddin, Mokhber, Rasid, \& Zamil. (2016). Organizational citizenship behaviour in public sector: does job satisfaction play a role. International Journal of Economics and Financial Issues. 2016, 6(8), 376-381

Darmawanti, H., \& Herlina. (2013). Pengaruh kepuasan kerja dan komitmen organisasi terhadap organizational citizenship behavior (ocb). Jurnal Economia Vol 9, No. 1

Golestaneh, S.M. (2014). The relationship between psychological capital and organizational citizenship behavior. Management and Administrative Sciences Review, 3(7), 1165-1173

Görgens-Ekermans, G., \& Herbert, M. (2013). Psychological capital: internal and external validity of the psychological capital questionnaire (pcq-24) on a south african sample. SA Journal of Industrial Psychology, 39(2). 12 pages

Gunawan, H., \& Masruroh. (2013). Pengaruh kepuasan kerja dan komitmen organisasi terhadap organizational citizenship behavior (ocb) di ramayana department store pasar kopro. Tesis Fakultas Ekonomi dan Bisnis Bina Nusantara

Gunawan, I Kadek, \& Netra. (2017). Pengaruh kepemimpinan transformasional dan komitmen organisasional terhadap organizational citizenship behavior karyawan. E-Journal Manajemen Unud, Vol 6. No.4

Hyo Sun Jung., \& Hye Hyun Yoon, (2015). The impact of employees' positive psychological capital on job satisfaction and organizational citizenship behaviors in the hotel. International Journal of 
Contemporary Hospitality Management, Vol. 27 Issue: 6, pp.1135-1156 https://doi.org/10.1108/IJCHM-01-2014-0019.

Jogiyanto \& Abdillah. (2009). Konsep dan aplikasi pls (partial least square) untuk penelitian empiris. Yogyakarta:BPFE-Yogyakarta

Julianti \& Dewayani. (2015). Pengaruh psychological capital terhadap komitmen organisasi dan perilaku kewargaorganisasian pada karyawan. Jurnal Psikologi, Vol. 8

Kurniawan, A. (2015). Pengaruh komitmen organisasi terhadap organizational citizenship behavior (ocb) pt x bandung. Jurnal Manajemen, Vol 15, No 1

Liwarto \& Kurniawan. (2015). Hubungan psycap dengan kinerja karyawan PT. X Bandung. Jurnal Manajemen, Vol.14, No.2

Luthans. (2005). Organizational behavior. Teenth Edition. International Edition. United States. McGraw-Hill

Luthans, F., Youssef, C., \& Avolio, B. (2007). Psychological capital: developing the human competitive edge. NY: Oxford University Press.

Luthans, F., Norman, S.M., Avolio, B.J., \& Avey, J.B. (2008). The mediating role of psychological capital in the supportive organizational climate: employee performance relationship. Journal of Organizational Behavior, 29(2), 219-238

Luthans, F. (2011). Organizational behavior: an evidence-based approach 12th edition. New York: McGraw-Hill.

Luthans, F., \& Mhatre, K.H. (2011) Meta-analysis of the impact of positive psychological capital on employee attitudes, behaviors, and performance. Human Resource Development Quarterly, 22, 127-152.

Luthans, F., Carolyn, M, \&. Youssef-Morgan. (2017). Psychological capital: an evidence-based positive approach. Annual Review of Organizational Psychology and Organizational Behavior, 4:1, 339-366

Mehboob. (2012). Job satisfaction as a predictor of organizational citizenship behavior a study of faculty members at business institutes. Interdisciplinary Journal of Contemporary Research In Business, Vol.3, No.9

Organ, D.W. (1988). Organizational citizenship behavior: the good soldier syndrome. Lexington Books.

Prihatsanti, U. (2017). Literature Review: The Role of Psychological Capital among Indonesian's Worker. Journal of Educational, Health and Community Psychology, Vol 6, No 3, 2017, E-ISSN 2460-8467

Purnomo, A.K. (2019). Pengolahan riset ekonomi jadi mudah dengan ibm spss. Surabaya: Jakad Publishing.

Rahmayanti, Febriana, \& Dewi. (2014). Faktor-faktor yang mempengaruhi organizational citizenship behavior (OCB). Jurnal Ecopsy Vol 1, No.3

Robbins, S \& Judge, T. (2015). Perilaku organisasi. Edisi 16. Jakarta: Salemba Empat

Sedarmayanti \& Kuswanto. (2015). Pengaruh servant leadership, komitmen, organizational citizenship behavior (studi pada rumah sakit immanuel bandung). Jurnal Ilmu Administrasi, Volume 12 (3)

Sopiah. (2008). Perilaku organisasional. Yogyakarta: Penerbit Andi.

Susanto. (2015). Analisis pengaruh kepemimpinan dan kepuasan kerja karyawan terhadap terjadinya organizational citizenship behavior (ocb) di restoran hachi-hachi Tunjungan plaza Surabaya. Jurnal Hospitality dan Manajemen Jasa, Vol.3(1)

Triyanto, A., \& Santosa, T. E. C. (2009). Organizational citizenship behavior (ocb) dan pengaruhnya terhadap keinginan keluar dan kepuasan kerja karyawan. Jurnal Manajemen, 7(2): p1-13

Umar, H. (2019). Metode riset manajemen perusahaan (langkah cepat dan tepat menyusun tesis dan disertasi). Jakarta: PT Gramedia Pustaka Utama.

Unal, O.F. (2013). Relationship between the facets of job satisfaction and the dimensions of organizational citizenship behavior: mediating role of organizational commitment. The Journal of Faculty of Economics and Administratives Sciences, 18 (1).

Unal. (2013). Relationship between the dimensions of organizational citizenship behavior and the facets of job satisfaction (an empirical study in a group of companies in Turkey. The Journal of WEI International Academic: Conference Proceedings

Www.bps.go.id 
Jurnal Manajemen Maranatha — Vol. 19 Nomor 1, November (2019) 